\section{Commentary: Late outcomes for survivors of the arterial switch operation: The glass is at least half-full}

\author{
Joseph B. Clark, MD
}

Following decades of accruing experience with the arterial switch operation, early and intermediate outcomes have become exceedingly well described. Further characterization of late patient outcomes remains an ongoing pursuit. Fricke and colleagues ${ }^{1}$ advance that understanding with their latest contribution on long-term outcomes. Although many findings are consistent with prior reports, the study shines a light on the potential challenges facing adult survivors.

In this large series spanning more than 30 years, early mortality was $3.3 \%$ and was remarkably stable across operative eras. The increased risk associated with the presence of a ventricular septal defect was again demonstrated, with these patients experiencing twice as much early mortality, late reintervention, and late reoperation. Although early survival may have been primarily driven by coronary artery status (most early deaths were due to myocardial ischemia), late outcomes did not appear to be influenced by coronary troubles. Coronary reoperations were rare and were typically confined to the early postoperative period; overall freedom from coronary reoperation was $99 \%$ at 25 years. With no patient deaths beyond 14 months, late survival was superb at $95 \%$ at 25 years. Good myocardial health was also the rule, as $98 \%$ of patients with available data showed normal ventricular function and Class I functional status.

Although late coronary pathology was not appreciated, such was not the case for the outflow tracts. Not

\footnotetext{
From the Division of Pediatric Cardiac Surgery, Department of Pediatrics, Penn State Children's Hospital, Hershey, Pa.

Disclosures: The author reported no conflicts of interest.

The Journal policy requires editors and reviewers to disclose conflicts of interest and to decline handling or reviewing manuscripts for which they may have a conflict of interest. The editors and reviewers of this article have no conflicts of interest.

Received for publication Feb 15, 2021; revisions received Feb 15, 2021; accepted for publication Feb 17, 2021; available ahead of print Feb 22, 2021

Address for reprints: Joseph B. Clark, MD, Division of Pediatric Cardiac Surgery, Department of Pediatrics, Penn State Children's Hospital, 500 University Dr, H085, Hershey, PA 17033 (E-mail: jclark7@ pennstatehealth.psu.edu).

J Thorac Cardiovasc Surg 2022;163:222-3

$0022-5223 / \$ 36.00$

Copyright (c) 2021 by The American Association for Thoracic Surgery

https://doi.org/10.1016/j.jtcvs.2021.02.059
}

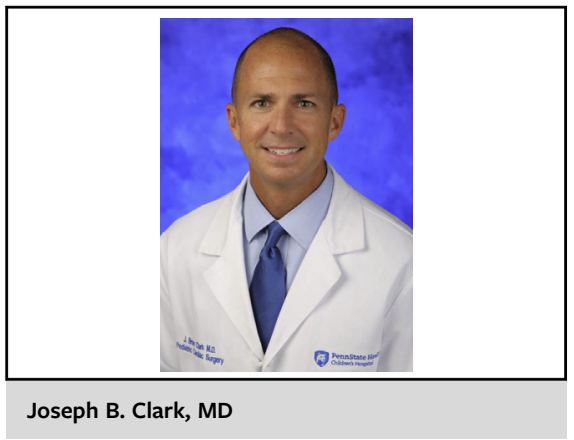

CENTRAL MESSAGE

Although overall outcomes

remain encouraging, late survi-

vors of the arterial switch oper-

ation are at risk for progressive

neoaortic root dilation and valve

regurgitation.

surprisingly, reintervention and reoperation were most commonly required for the neopulmonary root and pulmonary arteries. Notably, the authors identified burgeoning left-sided disease in the neoaortic root and valve as a principal finding. Although the overall cohort showed a $3.1 \%$ rate of at least moderate neoaortic regurgitation (AR) at a median of 15 years, the rate increased to $6.3 \%$ in those with 25 -year follow-up. Hampered by the lack of serial imaging data, the temporal progression of AR could not be further elucidated. Nonetheless, the surgical results offer some longitudinal insight as freedom from neoaortic root or valve reoperation decreased from $96 \%$ at 10 years to $92 \%$ at 25 years. In patients with 25-year follow-up, the incidence of moderate or greater $\mathrm{AR}$ and neoaortic valve replacement combined to reach $15 \%$.

These findings corroborate prior studies showing late progression of neoaortic valve disease. van der Palen and colleagues ${ }^{2}$ observed neoaortic root dilatation without stabilization during early adulthood, leading to moderate or greater AR in $31 \%$ by 25 years. Nakayama and colleagues ${ }^{3}$ also documented progressive $\mathrm{AR}$ in adulthood, with more than moderate AR worsening from $9 \%$ at 20 years to $18 \%$ at 30 years, eventually yielding a freedom from neoaortic valve reoperation of $91 \%$ at 30 years.

Accordingly, for long-term survivors of the arterial switch operation, the neoaortic root and valve will require 
lifetime surveillance and may necessitate reoperation in a fraction of patients. Despite this potential disease burden, the vast majority of patients in this series appear to have realized excellent long-term outcomes. Depending on one's perspective, this ever-evolving story may be likened to the glass that is seen as either half-empty or half-full. Overall, these results seem to argue in favor of the latter.

\section{References}

1. Fricke TA, Buratto E, Weintraub RG, Bullock A, Wheaton G, Grigg L, et al Long-term outcomes of the arterial switch operation. J Thorac Cardiovasc Surg. 2022;163:212-9.

2. van der Palen RLF, van der Bom T, Dekker A, Tsonaka R, van Geloven N Kuipers IM, et al. Progression of aortic root dilatation and aortic valve regurgitation after the arterial switch operation. Heart. 2019;105:1732-40.

3. Nakayama Y, Shinkawa T, Matsumura G, Hoki R, Kobayashi K, Niinami H. Late neo-aortic valve regurgitation long after arterial switch operation. Ann Thorac Surg. 2019;108:1210-6. 